labour and delivery and may contribute in part to the reduced incidence of fetal acidosis in our series. The incidence of breech extraction has not increased with this technique and control of the fetus at delivery has been uniformly good.

Although the hazards of breech delivery are well established for both the small and large fetus, the long-term sequelae of any breech delivery remain to be established and we look forward to the findings of Dr. Eliot and Mr. Hill in relation to this problem.We are, etc.

P. DONNI

Jessop Hospital for Women

D. NICHOLAS

Jessop Heffid

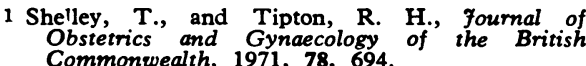

Congenital Malformations and their Control SiR,-Professor C. R. Lowe (26 August, p. 515) concludes that "because a valuable therapeutic substance has been shown to be teratogenic to laboratory animals at high doses, this does not necessarily mean that it will be teratogenic to the human embryo when the mother is on much lower therapeutic doses

Thereby he falls into the common fallacy of inferring innocuousness of a drug from the fact that only high multiples of its human therapeutic dose are toxic to animals. This reasoning ignores the often huge interspecies differences in drug responsiveness and the empirical rule that for producing the same effect, be it toxic or therapeutic, the usual laboratory animals require much larger doses per $\mathrm{kg}$ body weight than does man. It is meaningless to think of toxic animal doses as being "high" in terms of the human therapeutic doses, because for most drugs the therapeutic doses are also "high" in animals. Drawing inferences from such a combarison to the potential human toxicity of drugs may gravely underestimate it; in fact, the conclusion often is that there is no human toxicity to worry about.

The following data on thalidomide illustrate the point:

Although the routes by which these doses were given were not the same in all instances, the data are suited for being applied to the problem of proper interpretation of animal toxicity data. If, before it was marketed, thalidomide had been tested for teratogenicity, it would have been found that its teratogenic doses in the mouse, rat, and $\operatorname{dog}$ were 60,100 , and 200 times greater than the therapeutic human dose. By the reasoning set forth in Professor Lowe's article, this would have meant that the drug was probably not teratogenic to the human embryo. From the ratios of the teratogenic to the therapeutic doses in the three animal species it had to be expected, however, that thalidomide would produce malformations The ratios would also have shown that the drug would be teratogenic not only at therapeutic doses well below the threshhold dose for maternal toxicity-the tragic lesson of medical use experience-but also at doses that are below the threshhold even for therapeutic effects.-I am, etc.

HERBERT A. WENDEL University of Oregon Medical School, Portland, Oregon, U.S.A.

1 Kalter, H., Teratology of the Central Nervous System. 1968.

Barnes, C. D., and Eltherington, L. G., Drug
Dosage Dosage in Laboratory Animals
University of California Press, 1964.

\section{Tests of Sensitivity of Staphylococci to Methicillin}

SIR,-Tests of the sensitivity of staphylococci to methicillin in the hospital laboratory are inconvenient because of the characteristics of methicillin-resistant strains. Individual cocci do not appear to be uniformly resistant when grown on ordinary nutrient media at $37^{\circ} \mathrm{C}$; some show a slight resistance and a few are highly resistant. ${ }^{1}$ The highly resistant cells grow relatively slowly in the presence of methicillin, ${ }^{2}$ and therefore in standard disc diffusion tests it is difficult to distinguish between some resistant strains which show only a slight reduction in zone size and fully sensitive organisms.

To produce acceptable results with the disc diffusion test most laboratories employ one of two modifications which allow resistant organisms to grow up to the methicillin disc. Either the plates are incubated at $37^{\circ} \mathrm{C}$ and $5 \% \mathrm{NaCl}$ is incorporated in the medium ${ }^{3}$ or plates are incubated at $30^{\circ} \mathrm{C} .4^{4}$ With both techniques a heavy inoculum is used, usually a turbid broth culture, and the plates are incubated for 18 hours. Consequently, when penicillin-resistant staphylococci are isolated from infected material and the knowledge of their methicillin sensitivity is required there may be a delay. This is all the more inconvenient as methicillin sensitivity is usually used as the indicator of cloxacillin sensitivity, since routine sensitivity tests with cloxacillin give unsatisfactory results. ${ }^{5}$

We thought that a methicillin sensitivity test that could be completed within the working day would be of practical value, and we devised the one described below and evaluated it with 56 standard strains of staphylococci, 30 of which were methicillinresistant and 26 methicillin-sensitive. Twenty-five of the resistant strains and all of the sensitive strains were supplied by the Central Public Health Laboratory, Colindale. The other five resistant strains were supplied by $\mathrm{Mr}$. J. H. Hewitt.

We melted $10 \mathrm{ml}$ of Oxoid diagnostic sensitivity test agar containing added $5 \% \mathrm{NaCl}$ and kept it at $50^{\circ} \mathrm{C}$. To this was added $0.1 \mathrm{ml}$ of a solution of triphenyltetrazolium chloride (TTC) and $0.1 \mathrm{ml}$ of a bacterial suspension. The TTC solution was prepared by adding $750 \mathrm{mg}$ TTC

\begin{tabular}{|c|c|c|c|c|}
\hline & Man & Mouse & Rat & Dog \\
\hline A. Lowest teratogenic dose' $(\mathrm{mg} / \mathrm{kg}) \ldots$ & 0.5 & 30 & 50 & 100 \\
\hline $\begin{array}{l}\text { B. } \\
\text { dose }(\mathrm{mg} / \mathrm{kg}) . .\end{array}$ & 0.5 & $\begin{array}{l}100 \text { (p.o.); } \\
500 \text { (i.p.) }\end{array}$ & 550 (i.p.) & $\begin{array}{l}65 \text { (i.p.); } \\
300 \text { (i.m.) }\end{array}$ \\
\hline Ratio A:B & 1 & $0.3 ; 0.06$ & 0.09 & $1.54 ; 0.33$ \\
\hline
\end{tabular}

p.o. $=$ per os; i.p. $=$ intraperitoneal; i.m. $=$ intramuscular. to $100 \mathrm{ml}$ distilled water, and it was sterilized by Millipore filtration and stored in the dark. To prepare the bacterial suspension colonies of each strain of staphylococcus were taken from a blood agar plate and emulsified in $0.5 \mathrm{ml}$ normal saline until the turbidity equalled that of a standard made by adding $0.25 \mathrm{ml}$ of $1 \% \mathrm{H}_{2} \mathrm{SO}_{4}$

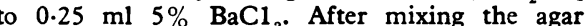
was used to prepare a pour plate. When this was set a disc containing $10 \mu \mathrm{g}$ methicillin was applied to the surface. Plates were incubated for four hours at $37^{\circ} \mathrm{C}$ with the bottom of each plate in contact with the metal shelf of the incubator. When the plates were examined bacterial growth was indicated by a change in the colour of the medium from its natural clear, pale yellow to pink owing to the reduction of TTC to triphenylformazan. Sensitivity of the organism under test to methicillin was indicated by the inhibition of the colour change and thus a zone of inhibition around the methicillin disc. The size of the zone of inhibition was recorded as its diameter less the diameter of the disc. The test was also carried out without the addition of TTC. Bacterial growth was still visible after four hours' incubation, though the appearance was less striking.

The minimum inhibitory concentration of methicillin for each organism was measured in tube dilution tests. Doubling dilutions of methicillin were made in $1-\mathrm{ml}$ volumes of Oxoid nutrient broth No. 2. Each tube was inoculated with an $0.02-\mathrm{ml}$ drop of a turbid $4-6$ hour broth culture giving an inoculum of about $10^{6}$ viable organisms. After incubation the tubes were examined for turbidity without previous shaking. M.I.C.s were determined after 18 hours' incubation at $30^{\circ} \mathrm{C}$ and after 24 and 48 hours' incubation at $37^{\circ} \mathrm{C}$.

M.I.C.s of methicillin for the organisms under test measured at $37^{\circ} \mathrm{C}$ after 24 hours' incubation ranged from 1.6 to more than $100 \mu \mathrm{g} / \mathrm{ml}$ (fig. 1). When they were

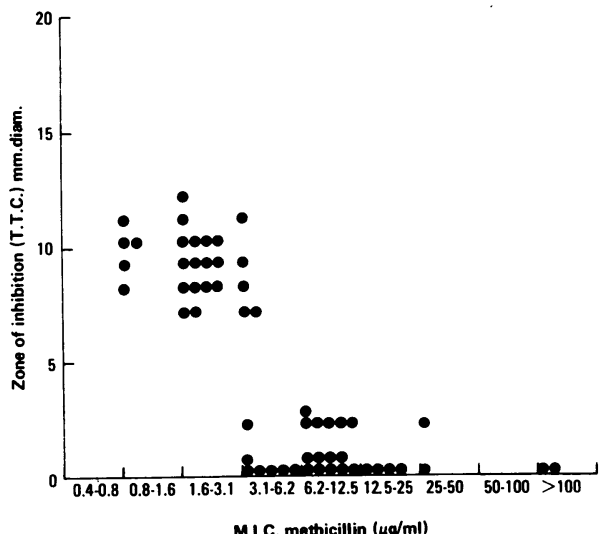

FIG. 1-Correlation of zone size (less diameter of disc) with M.I.C. methicillin determined after 2 hours incubation at $37^{\circ} \mathrm{C}$.

measured after 48 hours at $37^{\circ} \mathrm{C}$. or after 18 hours at $30^{\circ} \mathrm{C}$ there was a clear bimodal distribution. For sensitive strains they were found to be $12.5 \mu \mathrm{g}$ per $\mathrm{ml}$ or less, and for resistant strains $25 \mu \mathrm{g}$ per $\mathrm{ml}$ or more and usually more than $100 \mu \mathrm{g}$ per $\mathrm{ml}$. In the rapid sensitivity test with TTC the diameter of the zone of inhibition minus the diameter of the disc was more than $6 \mathrm{~mm}$ with sensitive strains, while with resistant strains it was less than $3 \mathrm{~mm}$ and usually there was no zone at all (fig. 2)

We confirmed that if a determination of the M.I.C. is to show a clear distinction between methicillin-sensitive and resistan strains cultures must be incubated for 48 hours at $37^{\circ} \mathrm{C}$ or for 18 hours at $30^{\circ} \mathrm{C}$. Under these conditions organisms which have an M.I.C. of $12.5 \mu \mathrm{g}$ per $\mathrm{ml}$ or less 